\title{
ADDISON'S DISEASE WITH HYPOFUNCTION OF THE PARATHYROID GLANDS
}

\author{
BY \\ H. SZCZEPAŃSKA and J. SAPIECHA \\ From the Clinic for Infectious Diseases of Childhood, Warsaw, Poland
}

(RECEIVED FOR PUBLICATION APRIL 2, 1959)

Addison's disease is an extremely rare disease in childhood, especially in girls. Since 1855,92 cases have been reported in children under $15 ; 26$ were 10-15 years old, so that under 10 years of age there are only 66 cases (the figures for 1855-1946 are from Jaudon (1946a, b, c), quoted by White and Sutton (1950); those for 1946-1957 are from Welch (1957)).

\section{Case Record}

Z.B., No. 6661/118, a girl born in 1952 , was the second child of elderly healthy parents; siblings aged 6, 3, 2 and 1 year were healthy, and no contact with tuberculosis or other infectious diseases was known. She was normally developed, and had never been ill before. She had not been vaccinated nor had B.C.G.; the tuberculin reaction was not known. She was a very active child, goodtempered and liked to take care of the younger children.

She became ill about two months before admission. The disease developed gradually without fever. She became weak, inactive, and tired quickly. Brown stains appeared on the skin, first on the face, and then on the body and extremities. She lost her appetite and vomited after meals, and a general decline set in. Her temper changed visibly: she became hypersensitive, cried often and never smiled. As these symptoms got worse, the child was admitted to a hospital where she was in contact with pertussis and was therefore brought to Warsaw and admitted to our clinic on December 12, 1957 with suspected Addison's disease.

On admission she appeared acutely ill. She lay motionless on one side with her knees pulled up to her chin, and moaned from time to time. She took no interest in her surroundings and, though conscious, would only answer in monosyllables. She greedily accepted liquids and frequent small feeds but vomited them immediately.

There were no constitutional anomalies except for clubbing of the fingers (Fig. 1). Her height was $3 \mathrm{ft} .5$ in. $(104 \mathrm{~cm}$.) and weight $2 \mathrm{st} .8 \mathrm{lb}$. $(16 \cdot 5 \mathrm{~kg}$.).

She had marked inanition, atrophy of the subcutaneous tissues, oedema of the lumbar region and ankles and marked dehydration. The skin was dry, rough and cold with patches of brown-grey pigmentation (Fig. 2). The face, neck, elbows, knees, dorsal surface of the fingers and toes and inguinal areas were dark brown, and in some places nearly black. The soles and palms of the hands were of a lighter colour. The mucous membrane of the mouth was pink and unpigmented. The tongue was smooth. Though there was no evidence of muscular atrophy the muscles were flaccid and weak.

Heart sounds were dull and the rate was regular at 120 per minute. The pulse was weak and soft. The internal organs and nervous system were normal.

The following investigations were performed:

B.P. 90/60; blood sedimentation rate $25 / 50$; $\mathrm{Hb} 81 \%$; R.B.C. 4,130,000; colour index 1.0; W.B.C. 6,600 (polymorphs $51 \%$, eosinophils $9 \%$, lymphocytes $40 \%$ ); blood group $\mathrm{O} \mathrm{Rh}+$; serum albumin $7 \cdot 1 \mathrm{~g} . \%$; sodium $310 \mathrm{mg} . \%$; potassium $16.5 \mathrm{mg}$. \%; chlorine (as $\mathrm{NaCl}$ ) $546 \mathrm{mg} . \%$; calcium $5.5 \mathrm{mg} . \%$; phosphorus $7.5 \mathrm{mg} . \%$; sugar $54.7 \mathrm{mg} . \%$; blood Wassermann negative.

Examination of the capillaries showed the flow to be slow and intermittent; there was dilatation of the loops at the apex and pallor; the number of loops was lessened and they were uneven; the efferent vessels were dilated. Professor J. Bogdanowicz confirmed that there was capillary stasis and lessened tension of the vessel walls.

The Thorn test was negative. Electrocardiography showed dysfunction of the blood flow of the heart muscle and a heart muscle lesion.

Urine: chemical and microscopical examination of the sediment showed no abnormality; Cl $220 \mathrm{mg}$. \%; sodium $266 \mathrm{mg} . \%$; potassium $117 \mathrm{mg} . \%$; daily $(24 \mathrm{hr}$.) 17 ketosteroids $2.8 \mathrm{mg} . \%$.

A radiograph of the thorax was normal, but the ossification centres of the hands were similar to those found in a 3-year-old child.

The tuberculin reaction (Moro, Mantoux 1:1,000) was negative. The basal metabolic rate was slightly increased. There was nothing frankly abnormal in the electroencephalogram (Koślacz). Cerebrospinal fluid was normal and the culture sterile. The gastric contents showed free hydrochloric acid, $35 \cdot 6$; total acidity $57 \cdot 2$. Examination of the larynx revealed a marked ozaena (Borkowska). Ophthalmological and neurological examination disclosed no abnormality (Naróg and Kirkow).

From the history and the clinical manifestations we diagnosed Addison's disease. 


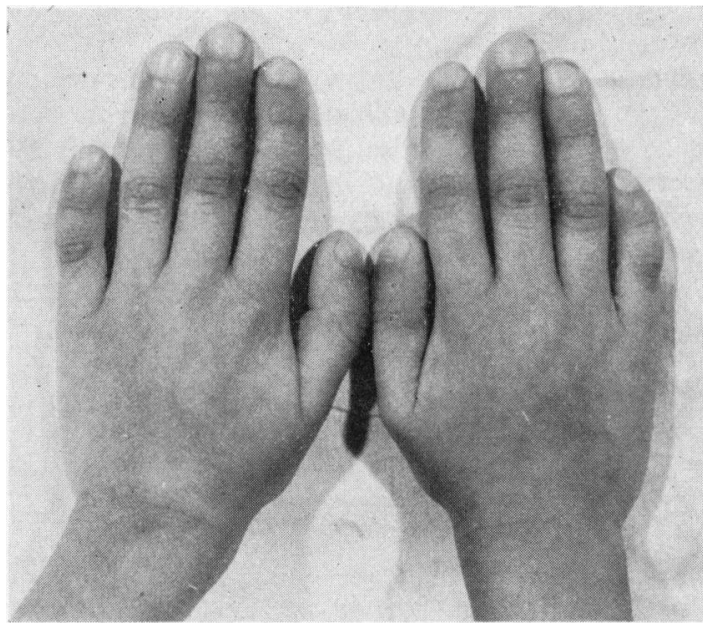

Fig 1.

Though we had no doubt of the diagnosis, there were some perplexing points; for example, the dysfunction of the other endocrine glands: hypofunction of the parathyroid (Leonard, 1946; Fargašová, 1958) was indicated by the lowered blood serum calcium and the increased phosphorus levels, by the normal renal function, the lack of change in the osseous system, and by the clinical picture of a dry, rough skin, onychorrhexis, poor dentition, numbness of the extremities, sensation of cold and a positive Chvostek test. The delay in ossification of the long bones suggested a concomitant thyroid dysfunction.

The diagnosis of acute Addison's disease called for energetic treatment. The patient was given desoxycorticosterone in oily solution intramuscularly in a dose of $10 \mathrm{mg}$.; then $5 \mathrm{mg}$. every day, every second day, and finally every third day. Simultaneously we added 4-5 g. salt daily to the child's food to increase the effect of the desoxycorticosterone. In addition she received $100 \mathrm{mg}$. of cortisone daily, with the dose reduced successively to 50 and $25 \mathrm{mg}$. We tried three times to give her prednisone instead of cortisone, but each time the child's condition deteriorated with vomiting and general weakness. The deterioration was probably due to the effect of the prednisone on the electrolyte balance.

We have not found any report in the literature in which cortisone was ineffective in Addison's disease. Because of the persistent vomiting in this case, sometimes 30 times during 24 hours, the marked dehydration, vascular collapse and grave heart condition, we administered from the outset a continuous intravenous drip of $5 \%$ glucose in physiological salt solution, a blood and plasma drip,

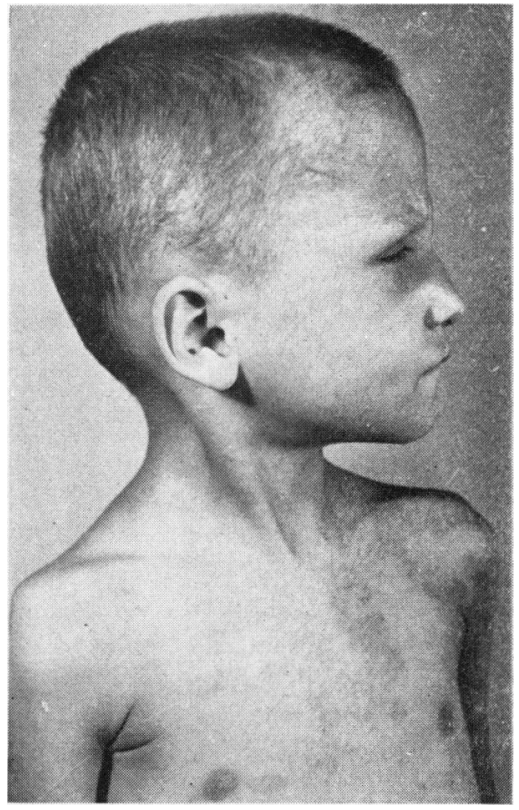

FIG 2.

oxygen and a vitamin complex in addition to the desoxycorticosterone and cortisone. Later on the child received thyroid orally in a dose of $0.06 \mathrm{~g}$. daily. After eight to 10 days' treatment the child gradually began to recover. She took an interest in her surroundings, she smiled and was glad to have her toys. The discoloration of her skin gradually became less marked, she vomited less and began to gain weight.

Three months after the child's admission a marked improvement was noted: she was good-tempered, smiling and active. However, in the fourth month her condition visibly worsened and, although a blood examination showed normal sugar, albumin and electrolyte values, she passed into a convulsed and insensible state which persisted for 35 hours. This was followed by an increasing dementia.

Our attempts to control her condition by transfusions and by hormone treatment were ineffective. Finally, in spite of prophylactic antibiotics, the child developed pneumonia and died on September 8, 1958, after eight months' treatment in the clinic. The clinical diagnosis was Addison's disease, hypoparathyroidism, bilateral lobar pneumonia, ozaena, dementia, cachexia and myocarditis.

At autopsy we found a confluent lobar pneumonia, mucopurulent tracheobronchitis, hypertrophy of the left heart, cortical atrophy of the suprarenal gland, hypertrophy of the clitoris, leptomeningeal oedema, 
inflammatory enlargement of the spleen and cachexia.

Microscopical examination revealed that in the suprarenals the medulla was unaffected, but the cortex showed extreme atrophy. The hypophysis was normal. The ovaries were normal, as were the thyroid and the pancreas. The thymus was atrophic with few Hassall's corpuscles. The brain was normal (Rosnowski).

We might have treated this case with greater success if the newest drugs, such as aldosterone and $\alpha$-fluorohydrocortisone had been available.

It is worth pointing out that, although the albumin-carbohydrate balance and the electrolyte balance were restored to normal, it proved impossible, finally, to control the mental deterioration, to restore the child's weight or to master the increasing prostration.

The autopsy confirmed the clinical diagnosis of Addison's disease, but there is no doubt that there was also some disturbance of the parathyroid glands, though, as they were not found at autopsy
(? atrophy), it was impossible to examine them histopathologically.

The autopsy did not throw any light on the mental deterioration and psychical disorders which persisted for a few months; they should probably be related to persistent and increasing anoxia of the cerebral cortex and to its abnormal carbohydrate metabolism.

Ozaena and clubbed fingers are extremely rare signs in Addison's disease.

\section{REFERENCES}

Fargašová, Irena (1958). Primary idiopathic hypoparathyroidism and Addison's disease in a 12-year-old girl. Čsl. Pediat., 13, 539.

Jaudon, J. C. (1946a). Addison's disease in children. J. Pediat., 28, 737 .

(1946b). Hypofunction of the adrenals in early life. Ibid., $29,696$.

(1946c). Addison's disease in an infant. J. clin. Endocrin., 6,558 .

Leonard, Martha F. (1946). Chronic idiopathic hypoparathyroidism with superimposed Addison's disease in a child. Ibid., 6, 493.

Welch, R. G. (1957). Addison's disease in a nine-year-old girl. Brit. med. J., 1, 980.

White, F. P. and Sutton, L. E. (1950). Addison's disease in a negro child. J. Pediat., 37, 778. 